\title{
Erratum to: Carbon and nitrogen isotopic ratios of urine and faeces as novel nutritional biomarkers of meat and fish intake
}

\author{
Gunter G. C. Kuhnle • Annemiek M. C. P. Joosen • \\ Catherine J. Kneale • Tamsin C. O'Connell
}

Published online: 5 December 2012

(c) Springer-Verlag Berlin Heidelberg 2012

\section{Erratum to: Eur J Nutr \\ DOI 10.1007/s00394-012-0328-2}

In the original publication, Table 2 was published incorrectly as the values for urine and faeces were inadvertently interchanged. The corrected table is given below.

The online version of the original article can be found under doi:10.1007/s00394-012-0328-2.

G. G. C. Kuhnle ( $\square)$

Department of Food and Nutritional Sciences, University of Reading, Whiteknights, PO Box 226, Reading RG6 6AP, UK e-mail: g.g.kuhnle@ reading.ac.uk

G. G. C. Kuhnle - A. M. C. P. Joosen

MRC Dunn Human Nutrition Unit, Wellcome Trust/MRC

Building, Cambridge, UK

\section{G. G. C. Kuhnle}

MRC Centre for Nutritional Epidemiology in Cancer Prevention and Survival, Department of Public Health and Primary Care,

University of Cambridge, Cambridge, UK

\section{J. Kneale · T. C. O’Connell}

McDonald Institute for Archaeological Research,

University of Cambridge, Cambridge, UK

T. C. O'Connell

Department of Archaeology and Anthropology,

University of Cambridge, Cambridge, UK
Table 2 Isotope ratios $\left(\delta^{13} \mathrm{C}\right.$ and $\left.\delta^{15} \mathrm{~N}\right)$ of blood, faeces and urine (median and inter-quartile range)

\begin{tabular}{lcll}
\hline Diet group & $n$ & $\delta^{13} \mathrm{C}(\%)$ & $\delta^{15} \mathrm{~N}(\%)$ \\
\hline Blood $^{\mathrm{a}}$ & & & \\
Fish & 13 & $-22.7(-23.0$ to -22.6$)$ & $8.5(8.4-8.6)$ \\
Meat/fish & 11 & $-23.0(-23.2$ to -22.6$)$ & $8.5(8.3-8.7)$ \\
Meat & 14 & $-22.8(-23.1$ to -22.5$)$ & $8.5(8.3-8.7)$ \\
Vegetarian & - & - & - \\
Urine $^{\text {b }}$ & & & \\
Fish & 14 & $-23.2(-23.4$ to -22.9$)$ & $6.7(6.3-6.8)$ \\
Meat/fish & 13 & $-24.0(-24.3$ to -23.5$)$ & $5.7(5.2-6.0)$ \\
Meat & 14 & $-24.3(-24.4$ to -23.8$)$ & $5.6(5.5-5.9)$ \\
Vegetarian & 4 & $-24.8(-25.0$ to -24.5$)$ & $3.5(3.4-3.8)$ \\
Faeces ${ }^{\text {b }}$ & & & \\
Fish & 14 & $-25.8(-26.2$ to -25.5$)$ & $7.8(7.3-8.1)$ \\
Meat/fish & 13 & $-26.4(-26.6$ to -26.2$)$ & $7.0(6.8-7.8)$ \\
Meat & 14 & $-26.5(-26.7$ to -26.3$)$ & $6.9(6.7-7.2)$ \\
Vegetarian & 4 & $-27.2(-27.4$ to -27.0$)$ & $5.0(4.5-5.4)$ \\
\hline
\end{tabular}

${ }^{a}$ No significant differences between diets $\left(p>0.6\right.$ for $\delta^{13} \mathrm{C}$ and $\delta^{15} \mathrm{~N}$, Kruskal-Wallis test)

b Significant differences between diets $\left(p<0.0005\right.$ for $\delta^{13} \mathrm{C}$ and $\delta^{15} \mathrm{~N}$, Kruskal-Wallis test) 